\title{
The role of empagliflozin in the management of type 2 diabetes by patient profile
}

\author{
This article was published in the following Dove Press journal: \\ Therapeutics and Clinical Risk Management \\ 5 May 2015 \\ Number of times this article has been viewed
}

\section{Maka S Hedrington \\ Stephen N Davis}

Department of Medicine, University of Maryland School of Medicine, Baltimore, MD, USA
Correspondence: Stephen N Davis Department of Medicine, University of Maryland School of Medicine, 22 South Greene Street, Room N3W42, Baltimore, MD 2I 20I, USA

Tel +l 4I0 3282488

Fax + I 4103288688

Email sdavis@medicine.umaryland.edu

\begin{abstract}
Current recommendations for the management of type 2 diabetes mellitus (T2DM) include patient-centered approach, ie, targeting glycemic control based on patient and disease characteristics. Ten different classes of oral and injectable anti-hyperglycemic agents have been developed for T2DM, including the newest class - sodium-glucose cotransporter 2 (SGLT2) inhibitors. Four members of the class with comparable glycemic efficacy and side effects have gained approval in the US and the rest of the world. This review covers empagliflozin - third approved SGLT2 inhibitor in the US. The drug has shown rapid absorption reaching peak levels in $\sim 2$ hours and an elimination half-life of $\sim 13$ hours. Empagliflozin is a highly selective SGLT2 inhibitor with 2600-fold higher affinity for SGLT2 compared with SGLT1. Oral administration results in a dose-dependent inhibition of the transporters with increased urinary glucose excretion and resultant reduction in plasma glucose. Its efficacy and safety have been shown in a number of studies conducted in many countries. Across the trials, significant improvements in primary and secondary efficacy end points have been demonstrated, including reductions in $\mathrm{HbA}_{1 \mathrm{c}}(\sim-0.8 \%)$, fasting plasma glucose $(\sim-2 \mathrm{mmol} / \mathrm{L})$, body weight $(\sim-2 \mathrm{~kg})$, and blood pressure (systolic $-4 \mathrm{mmHg}$ and diastolic $-2 \mathrm{mmHg}$ ). Similar to other SGLT2 inhibitors, empagliflozin does not increase the risk for hypoglycemia, and the most commonly reported side effects are urinary and genital tract infections. Although empagliflozin can be used as the first-line monotherapy, its current place in the treatment of T2DM appears to be as an add-on to other oral anti-hyperglycemic agent(s) or insulin at any stage of the disease.
\end{abstract}

Keywords: anti-hyperglycemic agents, diabetes, glucose, SGLT2

\section{Introduction to the management issues in the type 2 diabetes mellitus}

There are over 100 different drug formulations approved by the US Food and Drug Administration (FDA) for use in type 2 diabetes mellitus (T2DM), and yet, challenges in the management of the disease remain. The issues are usually associated with insufficient glycemic control and/or side effects of oral or injectable medications. Currently, six mechanisms targeted by oral agents offer lowering of blood glucose: (1) increased insulin production (sulfonylureas, meglitinides), (2) increased insulin sensitivity and reduced glucose production (biguanides, thiazolidinediones [TZD]), (3) inhibited breakdown of carbohydrates ( $\alpha$-glucosidase inhibitors), (4) increased insulin release and reduced glucose production (dipeptidyl peptidase-4 inhibitors), (4) inhibited renal glucose reabsorption (sodium-glucose cotransporter 2 [SGLT2] inhibitors), (5) modulation of the hypothalamic regulation of metabolism and increased insulin sensitivity (dopamine-2 agonists), and (6) an unknown primary physiological action (bile acid sequestrants). Injectable treatment options for T2DM include insulin and insulin analogs, amylin mimetics with slowing of gastric emptying time and inhibition of glucagon production, and glucagon-like peptide-1 (GLP-1) receptor agonists that increase insulin release and inhibit glucagon secretion. ${ }^{1,2}$ 
Key side effects of the above agents include hypoglycemia - insulin and sulfonylureas; gastrointestinal side effects (nausea, vomiting, diarrhea, abdominal cramping) - biguanides, $\alpha$-glucosidase inhibitors, GLP-1 receptor agonists, and amylin mimetics; and weight gain - insulin, sulfonylureas, meglitinides, and TZDs. ${ }^{1,3,4}$

Inadequate glycemic efficacy has also limited the widespread use of $\alpha$-glucosidase inhibitors, amylin mimetics, bile acid sequestrants, and dopamine- 2 agonists. ${ }^{4}$

\section{Overview of the clinical aspects of the main patient profiles in diabetes and treatment considerations}

The American Diabetes Association (ADA) and the European Association for the Study of Diabetes (EASD) are calling for a more patient-centered approach for diabetes care. ${ }^{1,2}$ ADA and EASD recommend choosing a target $\mathrm{HbA}_{1 \mathrm{c}}$ based on patient and disease characteristics. ${ }^{1}$ For example, tighter glycemic control with target $\mathrm{HbA}_{1 \mathrm{c}}<6.5 \%$ is recommended for newly diagnosed patients with a longer life expectancy, with low risks of hypoglycemia or other side effects, who do not have comorbidities or vascular complications, who are highly motivated, and who have social support readily available. For individuals newly diagnosed with T2DM, metformin remains the drug of choice, unless contraindicated or not tolerated (GI side effects). Although, SGLT2 inhibitors are also approved as an initial monotherapy, they are currently mostly used as second- or third-line agents. ${ }^{5}$

A newer approach is being considered for individuals who are newly diagnosed with T2DM with $\mathrm{HbA}_{1 \mathrm{c}} \geq 9 \%$. Since the chance of achieving near-normal glycemia with one agent is very low, ADA recommends starting dual combination therapy with metformin and a second agent. ${ }^{1}$ Based on patient and disease characteristics, insulin may also be initiated and, in fact, may be the best option in this patient category.

In individuals with T2DM who were started on metformin monotherapy but were unable to achieve target $\mathrm{HbA}_{1 \mathrm{c}}$ within 3 months, addition of a second anti-hyperglycemic agent is recommended. ${ }^{2}$ The 2015 position statement of ADA and EASD suggests considering SGLT2 inhibitors as reasonable options for addition to metformin. ${ }^{1}$ When triple combinations are required, initiation of insulin should be considered; otherwise, agents with the complementary mechanisms of action, eg, metformin + an SGLT2 inhibitor + a $\mathrm{TZD}^{6}$ or a sulfonylurea, should be chosen. ${ }^{7}$

In all, $\sim 80 \%$ of T2DM patients are either overweight or obese. ${ }^{8}$ In this patient group, as a common practice, medications with weight neutrality or reduction are favored (metformin, SGLT2 inhibitors, GLP-1 receptor agonists, and amylin mimetics).

\section{Review of pharmacology, mode of action, pharmacokinetics of empagliflozin Introduction to SGLT2 inhibitors and the mode of action}

SGLT2 inhibitors are the newest class of anti-diabetes drugs currently available on the market. The class targets the highest capacity subtype of sodium-coupled transporters (ie, SGLT2) that are responsible for the reabsorption of filtered glucose in the proximal tubules of kidneys (Figure 1). ${ }^{9}$ As a result, excess glucose is eliminated from the body, which can lead to an $\mathrm{HbA}_{1 \mathrm{c}}$ reduction of $\sim 1 \% .{ }^{10}$ Although SGLT2 normally transports $\sim 90 \%$ of the filtered glucose, its inhibition results in excretion of only $30 \%-50 \%$ of glucose (Figure 2), and therefore, the risk of hypoglycemia is low. An important advantage of SGLT2 inhibitors is the insulin-independent mechanism of action, which allows the class to be effective at any stage during the progression of T2DM. Additional benefits include weight loss ( - $2 \mathrm{~kg})$ and reduction in blood pressure (BP) (systolic: $\sim-3 \mathrm{mmHg}$ and diastolic: -2 $\mathrm{mmHg}){ }^{10,11}$

Currently, four SGLT2 inhibitors have gained approval from the US FDA, the European Medicines Agency, Therapeutic Goods Administration of Australia, and Pharmaceuticals and Medical Devices Agency of Japan: dapagliflozin (Farxiga ${ }^{\mathrm{TM}}$, marketed as Forxiga ${ }^{\mathrm{TM}}$ outside the US), canagliflozin (Invokana ${ }^{\mathrm{TM}}$ ), ipragliflozin (Suglat ${ }^{\mathrm{TM}}$ ), and empagliflozin (Jardiance ${ }^{\mathrm{TM}}$ ). The latter has been developed and marketed by Boehringer Ingelheim Pharmaceuticals in collaboration with Eli Lilly and Company. Empagliflozin was approved by FDA on August 1, 2014 as an addition to diet and exercise to improve glycemic control in T2DM adults. ${ }^{12}$ Recommended starting dose is $10 \mathrm{mg}$ /day. If greater glycemic control is required and $10 \mathrm{mg}$ is well tolerated, the dose can be increased to $25 \mathrm{mg} /$ day. ${ }^{13}$

\section{Chemistry}

Empagliflozin (C23H27ClO7; molecular weight: 450.9) is a highly selective inhibitor of SGLT2 with a half maximal SGLT2 inhibitory concentration $\left(\mathrm{IC}_{50}\right)$ of $3.1 \mathrm{nM}$, which is $>2,600$-fold higher compared with the $\mathrm{IC}_{50}$ for SGLT1 $(8,300 \mathrm{nM}){ }^{14}$

\section{Pharmacodynamics}

Pharmacodynamic (PD) properties of a single dose of empagliflozin (from $0.5 \mathrm{mg}$ to $800 \mathrm{mg}$ ) were investigated in healthy 


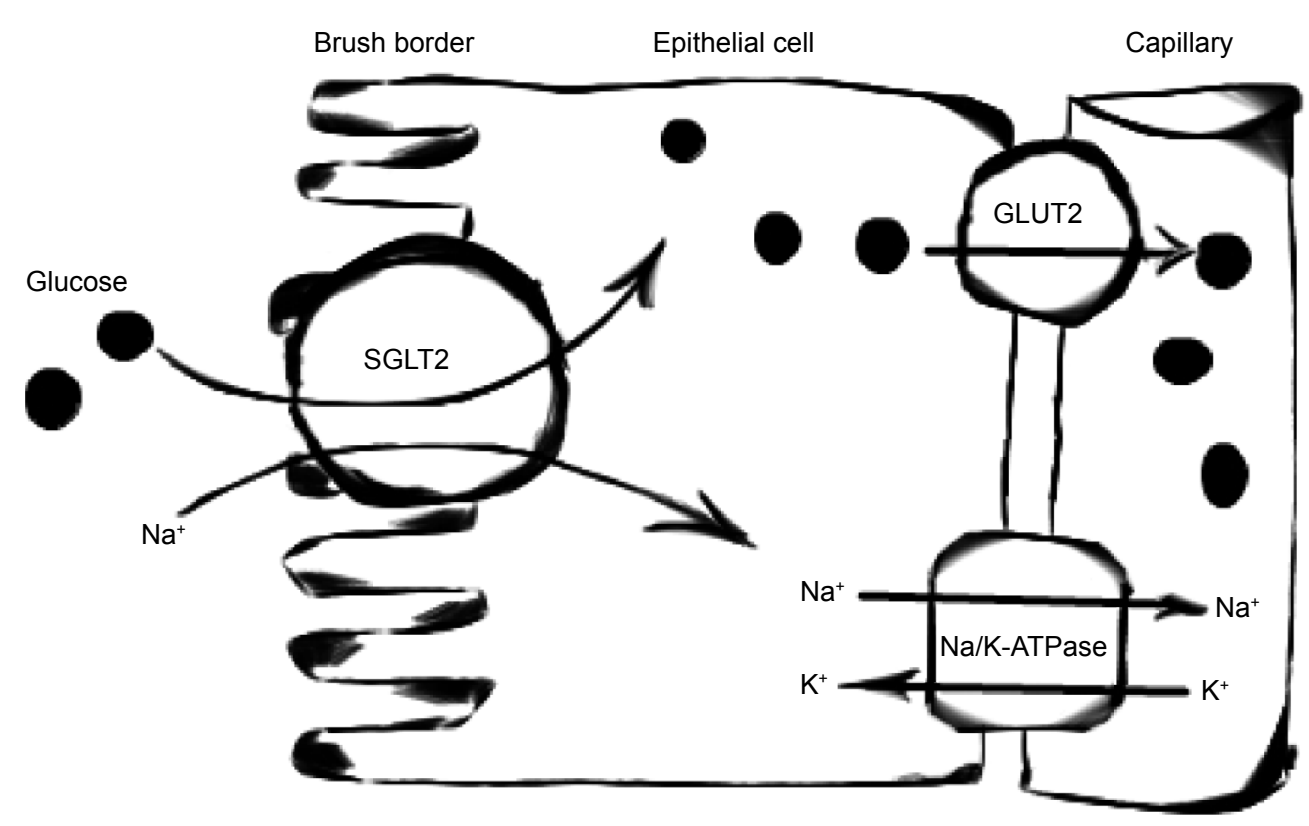

Figure I Sodium-glucose cotransporter 2.

Abbreviations: SGLT2, sodium-glucose cotransporter 2; GLUT2, glucose transporter 2.

males during two separate trials in Germany ${ }^{15}$ and Japan. ${ }^{16}$ The studies demonstrated that empagliflozin significantly inhibited glucose reabsorption (maximum effect - $100 \mathrm{mg}$ dose: $50 \%$ vs placebo $-0.6 \%$ ) and increased urinary glucose excretion (UGE) in a dose-dependent manner: from $20 \mathrm{~g} / 24$ hours with the $1 \mathrm{mg}$ dose to $\sim 76 \mathrm{~g} / 24$ hours with the $100 \mathrm{mg}$ vs $\sim 0.05 \mathrm{~g} / 24$ hours with placebo. The inhibition of the resultant glucosuria continued for up to 72 hours. ${ }^{16}$ There was a linear relationship between empagliflozin exposure and
UGE. However, time to reach maximum rate of UGE was not dose dependent and was similar in all groups (5-7 hours).

Heise et al studied PD parameters of a single dose of empagliflozin (10 mg, $25 \mathrm{mg}$, or $100 \mathrm{mg}$ ) following 4 weeks of treatment in $78 \mathrm{~T} 2 \mathrm{DM}$ individuals (mean $\mathrm{HbA}_{1 \mathrm{c}} \sim 7.2 \%$, duration of diabetes $\sim 6.3$ years) in a randomized, doubleblind, placebo-controlled manner (Table 1). ${ }^{17}$ The participants were being treated with lifestyle modification, monotherapy, or dual therapy that did not include TZDs. After an acute

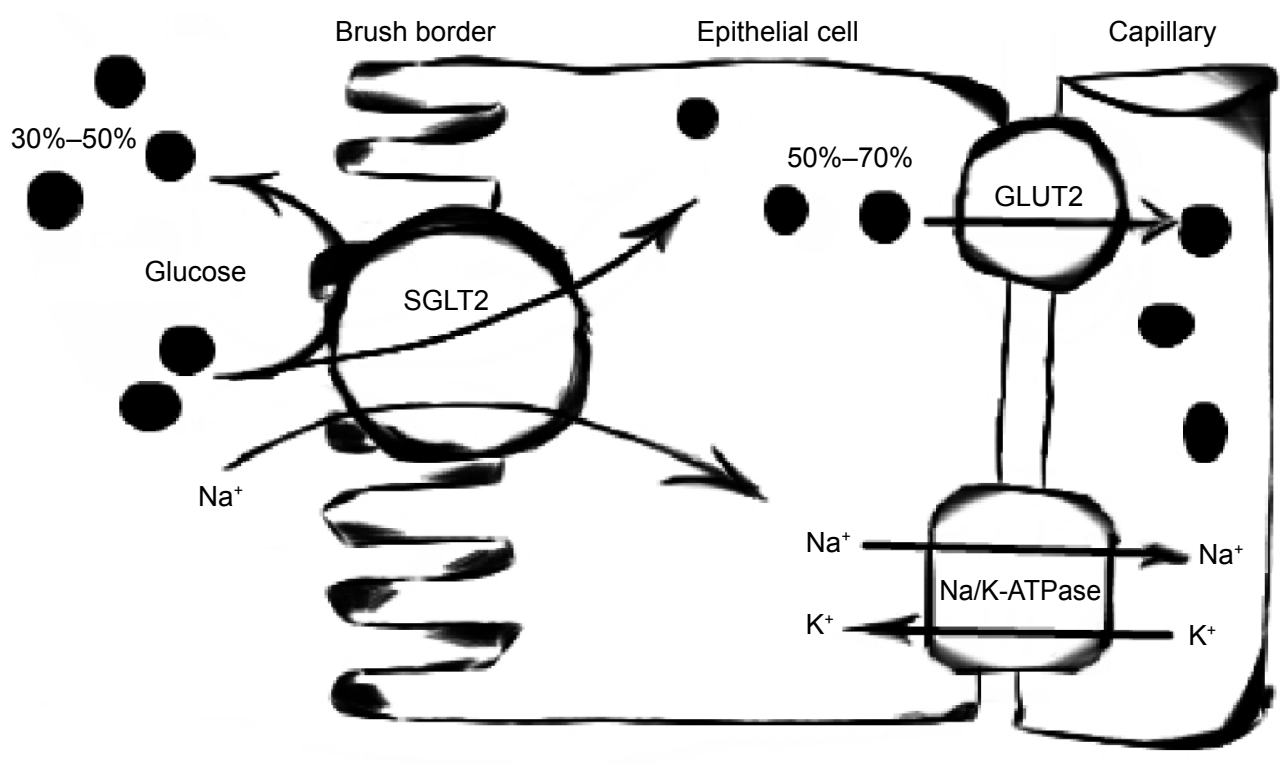

Figure 2 Mechanism of SGLT2 inhibition.

Abbreviations: SGLT2, sodium-glucose cotransporter 2; GLUT2, glucose transporter 2. 


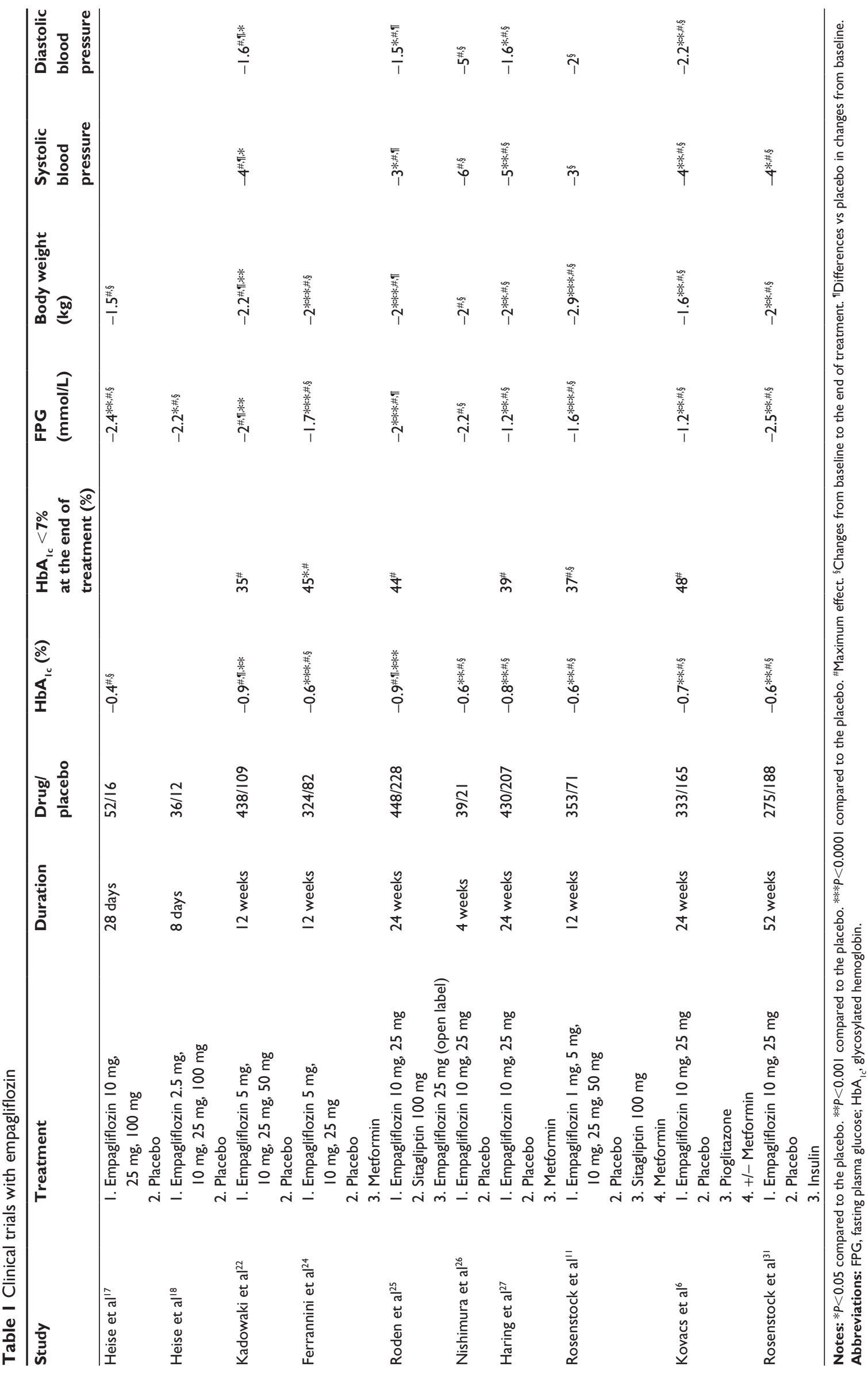


single-dose empagliflozin administration, mean cumulative UGE was inhibited by $36 \%$ (with $10 \mathrm{mg}$ ), 42\% (with $25 \mathrm{mg}$ ), and $45 \%$ (with $100 \mathrm{mg}$ ). The study also demonstrated that the acute effects of the drug on UGE did not change during the 4-week study. At the end of 28 days, trial reductions in fasting plasma glucose (FPG) levels $(-1.6 \mathrm{mmol} / \mathrm{L}$ in the $100 \mathrm{mg}$ group, $P<0.001)$ were also significantly compared to the placebo $(-0.2 \mathrm{mmol} / \mathrm{L})$. Similar results in individuals with $\mathrm{T} 2 \mathrm{DM}$ (mean $\mathrm{HbA}_{1 \mathrm{c}} \leq 8.5 \%$, duration of diabetes $\sim 6.3$ years) were demonstrated in another randomized, placebo-controlled trial conducted in Germany (Table 1). ${ }^{18}$

\section{Pharmacokinetics}

Empagliflozin has been demonstrated to have rapid absorption ( 2 hours) across a range of doses (1-100 mg). ${ }^{16}$ Half-life $\left(t_{1 / 2}\right)$ of the drug ranged from 7.8 hours to 11.7 hours, and the total clearance ranged from $140 \mathrm{~mL} / \mathrm{min}$ to $172 \mathrm{~mL} / \mathrm{min}$. Exposure to empagliflozin was also shown to be dose dependent, the $C_{\max }$ increasing from $37 \mathrm{nmol} / \mathrm{L}$ following a $1 \mathrm{mg}$ dose to $2,980 \mathrm{nmol} / \mathrm{L}$ with a $100-\mathrm{mg}$ dose. Empagliflozin remained measurable in urine for up to 72 hours following administration. It was estimated that $\sim 22 \%$ of the drug was excreted in the urine.

Pharmacokinetic $(\mathrm{PK})$ parameters in T2DM were studied in a randomized, double-blind, placebo-controlled, parallel-group trial in 78 individuals in three centers of Germany. ${ }^{17}$ Empagliflozin was rapidly absorbed, reaching $t_{\max }$ in 1.5 hours with all doses. Similar to the study in healthy individuals, drug exposure was dose proportional: $C_{\max }$ increased from $309 \mathrm{nmol} / \mathrm{L}$ in the $10 \mathrm{mg}$ group to $2,630 \mathrm{nmol} / \mathrm{L}$ in the $100 \mathrm{mg}$ group; $\mathrm{AUC}_{0-24}$ ranged from $1,550 \mathrm{nmol} \mathrm{h} / \mathrm{L}(10 \mathrm{mg})$ to $15,900 \mathrm{nmol} \mathrm{h} / \mathrm{L}$ (100 mg). Renal clearance of empagliflozin over 72 hours was $\sim 13 \%$ with all doses. The study also measured PK parameters after 4 weeks of treatment (steady state) and reported only a $10 \%$ difference compared to the acute administration studies: $C_{\max } 2,390 \mathrm{nmol} / \mathrm{L}, \mathrm{AUC}_{0-24} 18,700 \mathrm{nmol} \mathrm{h} / \mathrm{L}$, and renal clearance $17 \%$ in the $100 \mathrm{mg}$ group. Similar results were also obtained in another randomized, placebo-controlled trial of empagliflozin in T2DM individuals that investigated multiple doses of the drug administered over 8 days. ${ }^{18}$

A number of studies have investigated the PK interactions of empagliflozin with drugs typically used in combination therapy for T2DM. These studies have demonstrated that empagliflozin does not alter PK properties of metformin, ${ }^{15}$ sitagliptin, ${ }^{19}$ linagliptin, ${ }^{20}$ ramipril, digoxin, verapamil, and diuretics. ${ }^{21}$

\section{Clinical efficacy}

To investigate the clinical efficacy, empagliflozin has been studied either alone or in combination with other oral anti-hyperglycemic agents or as add-on to insulin in individuals with inadequately controlled T2DM. Several of these studies have been followed by extension trials, data from which are currently only available as abstracts.

\section{Monotherapy}

The key objective of monotherapy studies was to evaluate the effects of different therapeutic doses of empagliflozin on glycemic control as measured by reductions in $\mathrm{HbA}_{1 \mathrm{c}}$ and $\mathrm{FPG}$ and to provide additional data on body weight and BP.

A randomized, double-blind, placebo-controlled phase 2 trial investigated empagliflozin ( $5 \mathrm{mg}, 10 \mathrm{mg}, 25 \mathrm{mg}$, and $50 \mathrm{mg}$ doses) monotherapy for 12 weeks in 547 individuals with T2DM in Japan (Table 1). ${ }^{22}$ Drug-naïve participants underwent a 2-week placebo run-in period; for individuals on oral anti-hyperglycemic agents, placebo run-in was preceded by a 4-week washout period. Mean $\mathrm{HbA}_{1 \mathrm{c}}$ of all participants was $\sim 8 \%$, FPG was $\sim 8.7 \mathrm{mmol} / \mathrm{L}$, and $\mathrm{BMI}$ ranged from $18 \mathrm{~kg} / \mathrm{m}^{2}$ to $40 \mathrm{~kg} / \mathrm{m}^{2}$. The study demonstrated that $\mathrm{HbA}_{\mathrm{lc}}$ was significantly reduced in all empagliflozin groups and the differences from the placebo ranged from $-0.7 \%$ with the $5 \mathrm{mg}$ dose to $-0.9 \%$ with the $50 \mathrm{mg}$ dose $(P<0.001)$. In addition, more patients in the empagliflozin groups $(28 \%-35 \%, P<0.001)$ achieved $\mathrm{HbA}_{1 \mathrm{c}}<7 \%$ by the end of treatment compared to the placebo (3\%). Other efficacy end points, including FPG (difference vs placebo: $-1.5 \mathrm{mmol} / \mathrm{L}$ to $-2 \mathrm{mmol} / \mathrm{L}, P<0.001)$, body weight $(-1.6 \mathrm{~kg}$ to $-2.2 \mathrm{~kg}$, $P<0.001)$, and systolic BP $(-1.5 \mathrm{mmHg}$ to $4 \mathrm{mmHg}$, $P<0.001)$, were also significantly improved $(P<0.02)$ with all doses $(5-50 \mathrm{mg})$. The initial 12-week study was followed by a 40 -week extension trial ${ }^{23}$ during which improvements in glycemic control, body weight, and BP were maintained and remained significantly greater in the empagliflozin groups compared to the placebo.

Another large phase $2 \mathrm{~b}$ trial in T2DM individuals $(\mathrm{n}=408)$ with mean $\mathrm{HbA}_{\mathrm{lc}} \sim 8 \%$ and BMI $28 \mathrm{~kg} / \mathrm{m}^{2}$ compared $5 \mathrm{mg}$, $10 \mathrm{mg}$, and $25 \mathrm{mg}$ empagliflozin with placebo and open-label metformin (Table 1). ${ }^{24}$ The participants were either treatmentnaïve or on monotherapy that did not include TZDs, GLP-1 receptor agonists, or insulin. After 12 weeks of treatment, $\mathrm{HbA}_{1 \mathrm{c}}$ was significantly reduced in a dose-dependent manner (5 mg: $-0.4 \%$, $10 \mathrm{mg}:-0.5 \%, 25 \mathrm{mg}:-0.6 \%, P<0.0001$ ) compared to the slight increase in the placebo group $(0.09 \%)$. Maximum changes from baseline in other efficacy end points with the $25 \mathrm{mg}$ dose were as follows: $\mathrm{FPG}-1.7 \mathrm{mmol} / \mathrm{L}$ (vs $+0.04 \mathrm{mmol} / \mathrm{L}$ in the placebo group, $P<0.0001$ ) and body weight $-2 \mathrm{~kg}$ (vs $-0.7 \mathrm{~kg}$ in the placebo group, $P<0.0001$ ).

Drug-naïve T2DM individuals $\left(\mathrm{HbA}_{1 \mathrm{c}} \sim 8 \%, \mathrm{BMI} \sim 28 \mathrm{~kg} / \mathrm{m}^{2}\right.$, disease duration $\sim 5$ years) were also studied in a multicenter, 
randomized, placebo-controlled phase 3 trial to investigate the effects of 24 weeks treatment with $10 \mathrm{mg}(\mathrm{n}=224)$ and $25 \mathrm{mg}(\mathrm{n}=224)$ doses of empagliflozin in comparison with placebo $(n=228)$ and sitagliptin as an active comparator $(n=223)$ (Table 1). ${ }^{25}$ At week 24, compared with the placebo, changes in $\mathrm{HbA}_{1 \mathrm{c}}$ from baseline were $-0.7 \%$ in the $10 \mathrm{mg}$ group, $-0.9 \%$ in the $25 \mathrm{mg}$ group, and $-0.7 \%$ in the sitagliptin group $(P<0.001)$.

Effects of 4-week treatment with empagliflozin (10 mg or $25 \mathrm{mg}$ dose) on postprandial glucose (PPG) have been studied in Japanese T2DM individuals ( $\mathrm{HbA}_{1 \mathrm{c}} \sim 8 \%, \mathrm{BMI} \sim 24 \mathrm{~kg} / \mathrm{m}^{2}$, disease duration $\sim 5-10$ years) in a randomized, double-blind, placebo-controlled, parallel-group trial (Table 1). ${ }^{26}$ At the end of the treatment period, PPG was significantly improved in the $25 \mathrm{mg}$ group $(-6.8 \mathrm{mmol} \mathrm{h} / \mathrm{L}$ vs $-1 \mathrm{mmol} \mathrm{h} / \mathrm{L}$ in the placebo group, $P<0.001)$; FPG $(-2.2 \mathrm{mmol} / \mathrm{L}, P<0.001)$ was also significantly reduced compared to the placebo $(-0.3 \mathrm{mmol} / \mathrm{L})$.

\section{Combination therapy}

The sections below focus on phase 3 trials that investigated $10 \mathrm{mg}$ or $25 \mathrm{mg}$ empagliflozin doses to assess therapeutic efficacy of the drug as add-on to other oral agents or insulin.

\section{Add-on to metformin}

T2DM patients $\left(\mathrm{HbA}_{1 \mathrm{c}} \sim 8 \%, \mathrm{BMI} \sim 29 \mathrm{~kg} / \mathrm{m}^{2}\right.$, disease duration $\sim 5-10$ years) inadequately controlled with metformin were randomized in a double-blind manner to receive $10 \mathrm{mg}$ or $25 \mathrm{mg}$ of empagliflozin or placebo for 24 weeks (EMPA-REG MET) (Table 1). ${ }^{27}$ The reductions in $\mathrm{HbA}_{1 \mathrm{c}}$ were significantly greater in both empagliflozin groups (10 mg: $-0.7 \%$ and $25 \mathrm{mg}:-0.8 \%, P<0.001$ ) compared to placebo $(-0.1 \%)$. Improvements in secondary end points following $25 \mathrm{mg}$ empagliflozin included FPG $-1.2 \mathrm{mmol} / \mathrm{L}$ (placebo: $+0.4 \mathrm{mmol} / \mathrm{L}, P<0.001$ ), body weight $-2.5 \mathrm{~kg}$ (placebo: $-0.5 \mathrm{~kg}, P<0.001$ ), systolic BP $-5 \mathrm{mmHg}$ (placebo: $-0.4 \mathrm{mmHg}, P<0.001)$, and diastolic $\mathrm{BP}-1.6 \mathrm{mmHg}$ (placebo: $0 \mathrm{mmHg}, P<0.05$ ).

Similar results were demonstrated in a large multinational (16 countries), dose-ranging, double-blind, placebo-controlled phase 2 trial in 495 individuals with $\mathrm{T} 2 \mathrm{DM}\left(\mathrm{HbA}_{1 \mathrm{c}} \sim 8 \%\right.$, FPG $\left.\sim 9.7 \mathrm{mmol} / \mathrm{L}, \mathrm{BMI} \sim 31 \mathrm{~kg} / \mathrm{m}^{2}\right) .{ }^{11}$ The participants received empagliflozin (from $1 \mathrm{mg}$ to $50 \mathrm{mg}$ ), placebo, or open-label sitagliptin (100 mg/day) added to metformin ( $\geq 1,500 \mathrm{mg}$ or maximum tolerated dose) for 12 weeks. The trial demonstrated that, except for the $1 \mathrm{mg}$ dose group, change from the baseline in $\mathrm{HbA}_{1 \mathrm{c}}$ was significant with sitagliptin $(-0.5 \%)$ and all doses of empagliflozin $(\sim-0.5 \%$ with
$10 \mathrm{mg}, 25 \mathrm{mg}$, and $50 \mathrm{mg}, P<0.001)$ compared to placebo $(+0.2 \%)$. The percent of patients who achieved $\mathrm{HbA}_{1 \mathrm{c}}<7 \%$ by the end of treatment was $\sim 37 \%$ with $10 \mathrm{mg}, 25 \mathrm{mg}$, and $50 \mathrm{mg}$ doses $(P \leq 0.01)$ vs $15 \%$ with placebo and $34 \%$ with sitagliptin. The study also measured differences in FPG (maximum effect with $50 \mathrm{mg}$ : $-1.6 \mathrm{mmol} / \mathrm{L}$ vs $+0.3 \mathrm{mmol} / \mathrm{L}$ in the placebo group, $P \leq 0.0001$, and $-0.7 \mathrm{mmol} / \mathrm{L}$ in the sitagliptin group, $P \leq 0.01$ vs placebo) and body weight (maximum effect with $50 \mathrm{mg}$ : $-2.9 \mathrm{~kg}$ vs $-1.2 \mathrm{~kg}$ in the placebo group, $P \leq 0.0001$, and $-0.8 \mathrm{~kg}$ in the sitagliptin group). There was a non-statistical reduction in systolic and diastolic BP (50 mg group - systolic: $-3 \mathrm{mmHg}$ and diastolic: $-2 \mathrm{mmHg}$ vs $-2.2 \mathrm{mmHg}$ and $-1 \mathrm{mmHg}$ in the placebo group).

The 12-week study was followed by a randomized openlabel 78-week extension trial conducted in 21 countries. ${ }^{28}$ In all, $78 \%$ from the initial study continued the extension trial. The trial included six treatment groups: empagliflozin $10 \mathrm{mg}$ or $25 \mathrm{mg}$ monotherapy, metformin (active comparator), metformin and empagliflozin $10 \mathrm{mg}$ or $25 \mathrm{mg}$, and metformin with sitagliptin. At week 78, compared to the baseline of week 1, $\mathrm{HbA}_{1 \mathrm{c}}$ was improved equally with empagliflozin $25 \mathrm{mg}$ monotherapy $(-0.5 \%)$ and add-on to metformin $(-0.6 \%)$. The $25 \mathrm{mg}$ empagliflozin group combination with the metformin group also achieved highest reductions in FPG $(-1.8 \mathrm{mmol} / \mathrm{L})$, body weight $(-4 \mathrm{~kg})$, waist circumference $(-2.4 \mathrm{~cm})$, systolic BP $(-3 \mathrm{mmHg})$, and diastolic $\mathrm{BP}(-2 \mathrm{mmHg})$. In addition, more patients achieved $\mathrm{HbA}_{1 \mathrm{c}}<7 \%$ by the end of the treatment (45\%) compared to the other groups.

\section{Triple combination therapy}

The effects of empagliflozin (10 $\mathrm{mg}$ or $25 \mathrm{mg}$ ) as add-on to metformin and a sulfonylurea were investigated in a large ( $\mathrm{n}=666$ ) 24-week randomized, double-blind, placebo-controlled trial, ${ }^{7}$ followed by a $\geq 52$-week extension trial. ${ }^{29}$ At the end of the first treatment period, $\mathrm{HbA}_{1 \mathrm{c}}$ was significantly reduced in both empagliflozin groups $(-0.8 \%, P<0.001)$ compared to the placebo group $(-0.2 \%)$ and more patients achieved $\mathrm{HbA}_{1 \mathrm{c}}<7 \%$ (10 mg: 26\%, $25 \mathrm{mg}$ : 32\% vs placebo: $9 \%, P<0.001)$. There were significant improvements in key secondary end points: FPG $(-1.3 \mathrm{mmol} / \mathrm{L}$ in both empagliflozin groups vs $+0.3 \mathrm{mmol} / \mathrm{L}$ in the placebo group, $P<0.001)$, 2-hour PPG $(-2 \mathrm{mmol} / \mathrm{L}$ in both empagliflozin groups vs $-0.1 \mathrm{mmol} / \mathrm{L}$ in the placebo group, $P=0.003$ ), body weight (10 mg: $-2.2 \mathrm{~kg}, 25 \mathrm{mg}:-2.4 \mathrm{~kg}$ vs placebo: $-0.4 \mathrm{~kg}$, $P<0.001)$, waist circumference $(-1.5 \mathrm{~cm}$ in both empagliflozin groups vs -0.3 in the placebo group, $P=0.003$ ), and systolic BP $(-4 \mathrm{mmHg}$ in both empagliflozin groups vs $-0.3 \mathrm{mmHg}$ in the placebo group, $P=0.003$ ). In all, $71 \%$ of the initial participants 
entered into the extension trial..$^{29}$ At week 76, differences in the efficacy end points vs those of the placebo group were maintained in $\mathrm{HbA}_{1 \mathrm{c}}(-0.7 \%, P<0.001)$, body weight $(\sim-1.7 \mathrm{~kg}$, $P<0.001)$, and systolic BP $(-2 \mathrm{mmHg}, P<0.05)$.

A similar design study (24 weeks randomized, placebo controlled) investigated the effects of $10 \mathrm{mg}$ and $25 \mathrm{mg}$ empagliflozin as add-on therapy with metformin and/or pioglitazone (Table 1). ${ }^{6}$ After 24 weeks, reductions in $\mathrm{HbA}_{1 \mathrm{c}}$ were significantly greater in the empagliflozin groups (change from baseline in $10 \mathrm{mg}:-6 \%, 25 \mathrm{mg}:-7 \%, P<0.001)$ compared to the placebo group $(-1 \%)$. In all, $36 \%$ of participants in the $10 \mathrm{mg}$ group and $48 \%$ in the $25 \mathrm{mg}$ group (vs $12 \%$ in the placebo group) achieved $\mathrm{HbA}_{1 \mathrm{c}}<7 \%$ at week $24(P<0.001)$. Interestingly, glycemic efficacy was shown to be similar ( $-0.7 \%$ ) in groups receiving dual (empagliflozin with pioglitazone) and triple (empagliflozin + pioglitazone + metformin) combination therapies. The study also demonstrated significant improvements in FPG at week $24(-0.9 \mathrm{mmol} / \mathrm{L}$ in the $10 \mathrm{mg}$ group and $-1.2 \mathrm{mmol} / \mathrm{L}$ in the $25 \mathrm{mg}$ group vs increase in the placebo group $+0.4 \mathrm{mmol} / \mathrm{L}, P<0.001)$. Body weight and waist circumference were reduced in the empagliflozin groups (10 mg: $-1.6 \mathrm{~kg}$ and $-1.7 \mathrm{~cm}, 25 \mathrm{mg}$ : $-1.5 \mathrm{~kg}$ and $0.9 \mathrm{~cm}$, respectively, $P<0.001)$ and increased in the placebo group $(0.3 \mathrm{~kg}$ and $0.2 \mathrm{~cm}$, respectively). Systolic and diastolic BPs were also significantly reduced in both empagliflozin groups (10 mg: systolic $-3 \mathrm{mmHg}$ and diastolic $-2 \mathrm{mmHg}$, $25 \mathrm{mg}$ : systolic $-4 \mathrm{mmHg}$ and diastolic $-2 \mathrm{mmHg}, P \leq 0.01)$ compared to the slight increase in the placebo group (systolic: $0.7 \mathrm{mmHg}$, diastolic: $0.3 \mathrm{mmHg}$ ). In all, $61 \%$ participants of the first trial completed the 52-week extension trial in a double-blind manner. ${ }^{30}$ The extension trial demonstrated that changes in the efficacy end points $\left(\mathrm{HbA}_{1 \mathrm{c}}:-0.7 \%, P<0.001\right.$; body weight: $\sim-2 \mathrm{~kg}, P<0.001$; systolic BP: $-4 \mathrm{mmHg}$, $P<0.01$; diastolic BP: $-2 \mathrm{mmHg}, P<0.01)$ can be maintained for at least 76 weeks.

\section{Add-on to insulin}

Rosenstock et al investigated empagliflozin in combination with insulin in two trials (Table 1). ${ }^{31,32}$ The first trial studied addition of empagliflozin (10 $\mathrm{mg}$ or $25 \mathrm{mg}$ ) to basal insulin in 494 T2DM individuals ${ }^{31}$ and demonstrated significant improvements in glycemic control as well as secondary efficacy end points. $\mathrm{HbA}_{1 \mathrm{c}}$ at week 78 was reduced by $0.5 \%$ in the $10 \mathrm{mg}$ group and $0.6 \%$ in the $25 \mathrm{mg}$ group compared to reduction of $0.02 \%$ in the placebo group $(P<0.001)$; FPG was reduced by $-0.6 \mathrm{mmol} / \mathrm{L}$ in the $10 \mathrm{mg}$ group and $-2.5 \mathrm{mmol} / \mathrm{L}$ in the $25 \mathrm{mg}$ group vs increase in the placebo group $(0.2 \mathrm{mmol} / \mathrm{L})(P<0.001)$. Weight was reduced significantly in the empagliflozin groups $(10 \mathrm{mg}:-2.2 \mathrm{~kg}$, $25 \mathrm{mg}$ : $-2 \mathrm{~kg}, P<0.001)$ vs a $0.7-\mathrm{kg}$ weight gain in the placebo. Systolic BP was also reduced in the empagliflozin groups (10 mg: $-4 \mathrm{mmHg}, P<0.01 ; 25 \mathrm{mg}$ : $-2 \mathrm{mmHg}$ ) and slightly increased in the placebo group $(0.1 \mathrm{mmHg})$. In addition, at week 78 compared to the baseline, insulin dosage was significantly reduced in the empagliflozin groups (10 mg: $-1.2 \mathrm{IU}$, $25 \mathrm{mg}$ : $-0.5 \mathrm{IU}, P<0.01)$ compared to an increase in the placebo group (+5.5 IU). The second trial evaluated empagliflozin (10 mg or $25 \mathrm{mg}$ ) added to multiple daily injections of insulin in 563 obese, inadequately controlled $\left(\mathrm{HbA}_{1 \mathrm{c}} \sim 8.3 \%\right) \mathrm{T} 2 \mathrm{DM}$ individuals. ${ }^{32}$ Changes from baseline were assessed at weeks 18 and $52: \mathrm{HbA}_{1 \mathrm{c}}$ in the $10 \mathrm{mg}$ group was $-0.9 \%, 25 \mathrm{mg}$ group was $-1 \%$ vs $-0.5 \%$ in the placebo group at week $18(P<0.001)$. The glycemic control was further improved by week 52 with $\mathrm{HbA}_{1 \mathrm{c}}$ reduced by $-1.2 \%$ in the $10 \mathrm{mg}$ group and $-1.3 \%$ in the $25 \mathrm{mg}$ group vs $-0.8 \%$ in the placebo group. In addition, insulin doses in both empagliflozin groups were significantly reduced ( -9 to $-11 \mathrm{IU} /$ day, $P<0.01$ ). Compared to the placebo group, body weight was also reduced in the empagliflozin groups $(-2.4 \mathrm{~kg}$ to $-2.5 \mathrm{~kg}, P<0.001)$.

\section{Pooled analysis}

Pooled analysis of the efficacy data from four phase 3 trials ( $\mathrm{n}=2,477$ T2DM participants) demonstrated improved $\mathrm{HbA}_{1 \mathrm{c}}$ $(-0.8 \%$ in the $25 \mathrm{mg}$ group vs -0.08 in the placebo group), body weight ( $-2.3 \mathrm{~kg}$ in the $25 \mathrm{mg}$ group vs $0.2 \mathrm{~kg}$ gain in the placebo group), and reduction in $\mathrm{BP}$ (systolic $4 \mathrm{mmHg}$ and diastolic $2 \mathrm{mmHg}$ in the $25 \mathrm{mg}$ group vs $0.5 \mathrm{mmHg}$ and $0.6 \mathrm{mmHg}$, respectively, in the placebo group) at 24 weeks compared to baseline. ${ }^{33}$

Phase 3 clinical trials have investigated empagliflozin as a monotherapy or in combination with other anti-diabetes agent in over 14,000 individuals with T2DM.$^{34}$ All trials demonstrated improved glycemic control. Additional benefits included low risk of hypoglycemia and reductions in body weight and BP. Similar to other SGLT2 inhibitors, empagliflozin increased risk of mild-to-moderate genital and urinary tract infections.

\section{Comorbidities}

\section{Renal impairment}

Empagliflozin (10 $\mathrm{mg}$ or $25 \mathrm{mg}$ ) as add-on to existing therapy was studied in T2DM individuals with impaired renal function: stage 2 (eGFR (estimated glomerular filtration rate) $\left.60 \mathrm{~mL} / \mathrm{min} / 1.73 \mathrm{~m}^{2}-90 \mathrm{~mL} / \mathrm{min} / 1.73 \mathrm{~m}^{2}\right)$ or $3(\mathrm{eGFR}$ $30 \mathrm{~mL} / \mathrm{min} / 1.73 \mathrm{~m}^{2}-60 \mathrm{~mL} / \mathrm{min} / 1.73 \mathrm{~m}^{2}$ ) chronic kidney disease. ${ }^{35}$ The study demonstrated that compared to the baseline, at 24 weeks, $\mathrm{HbA}_{1 \mathrm{c}}$ was reduced in both stages of 
chronic kidney disease: $-0.7 \%$ and $-0.4 \%$, respectively, in the $25 \mathrm{mg}$ group $(P<0.0001)$.

\section{Liver impairment}

PK and PD properties of $50 \mathrm{mg}$ empagliflozin were studied in T2DM individuals with mild (Child-Pugh Class A, 5-6 points), moderate (Child-Pugh Class B, 7-9 points), or severe (ChildPugh Class C, 10-15 points) hepatic impairment compared to T2DM controls (with normal hepatic function) in an openlabel parallel-group study. ${ }^{36}$ The study demonstrated increased empagliflozin exposure (mild: 13,800 nmol $\times \mathrm{h} / \mathrm{L}$, moderate: $16,100 \mathrm{nmol} \times \mathrm{h} / \mathrm{L}$, and severe impairment: $19,000 \mathrm{nmol} \times \mathrm{h} / \mathrm{L}$ vs normal hepatic function: $10,800 \mathrm{nmol} \times \mathrm{h} / \mathrm{L}$ ) with increasing hepatic impairment. The study also assessed PD parameters and showed similar mean UGE between the groups (normal: 43 g/24 hours, mild: $36 \mathrm{~g} / 24$ hours, moderate: $38 \mathrm{~g} / 24$ hours, and severe: $40 \mathrm{~g} / 24$ hours).

\section{Hypertension}

A large, double-blind, randomized, placebo-controlled, multinational phase 3 trial has investigated the effects of 12 -week treatment with empagliflozin $(10 \mathrm{mg}$ or $25 \mathrm{mg}$ ) in 825 individuals with T2DM and hypertension (mean systolic BP: $130-159$ mmHg, mean diastolic BP: $80-99 \mathrm{mmHg}) .{ }^{37}$ The study demonstrated significant improvements in glycemic control as well as BP. The change from the baseline in $\mathrm{HbA}_{1 \mathrm{c}}$ at week 12 was $-0.6 \%$ (vs placebo) with the $10 \mathrm{mg}$ dose and $-0.7 \%$ with the $25 \mathrm{mg}$ dose $(P<0.001)$. Mean 24-hour systolic BP was reduced by $-3.4 \mathrm{mmHg}$ with the $10 \mathrm{mg}$ dose and $-4.2 \mathrm{mmHg}$ with the $25 \mathrm{mg}$ dose $(P<0.001)$. Changes in mean diastolic BP were $-1.4 \mathrm{mmHg}$ and $-1.7 \mathrm{mmHg}$ with $10 \mathrm{mg}$ and $25 \mathrm{mg}$ doses, respectively $(P<0.001)$.

\section{Safety and tolerability}

Across the initial clinical studies as well as longer-term extension trials, empagliflozin has been shown to be safe and generally well tolerated. ${ }^{15-20,22-38}$ Empagliflozin safety was assessed in a systemic review and meta-analysis of 10 randomized controlled trials in 6,203 T2DM participants. ${ }^{38}$ The study demonstrated that treatment with empagliflozin did not increase the risk of hypoglycemia. The total number of hypoglycemic events was 195 in the $25 \mathrm{mg}$ empagliflozin group and 186 in the placebo group. Majority of these episodes occurred in trials that investigated patients who were also treated with agents known to increase risk of hypoglycemia (sulfonylurea, insulin). ${ }^{31,38}$ There were only eight participants (out of 3,165) who experienced severe hypoglycemia - requiring assistance by another person. Liakos et al also analyzed the risk of urinary and genital tract infections in the empagliflozin-treated individuals. While the risk of urinary tract infections was not increased, there were more episodes of genital tract infection (mainly in male participants) in the empagliflozin groups compared to the placebo group. ${ }^{38}$

Another review of phase 3 clinical trials reported effects of empagliflozin on plasma low-density lipoprotein (LDL), high-density lipoprotein (HDL), and triglycerides. ${ }^{33}$ LDL was increased in empagliflozin $10 \mathrm{mg}(3.1 \mathrm{mg} / \mathrm{dL})$ and $25 \mathrm{mg}(3.9 \mathrm{mg} / \mathrm{dL})$ groups compared to the placebo group $(0.8 \mathrm{mg} / \mathrm{dL})$. HDL was also increased by $2.7 \mathrm{mg} / \mathrm{dL}$ in both empagliflozin groups vs there was no change in the placebo group. There was a reduction in triglycerides in the $10 \mathrm{mg}$ $(-9.7 \mathrm{mg} / \mathrm{dL})$ and $25 \mathrm{mg}(-1.8 \mathrm{mg} / \mathrm{dL})$ groups vs increase in the placebo group $(+2.7 \mathrm{mg} / \mathrm{dL})$. The clinical significance of these results has yet to be determined.

\section{Ongoing trials}

FDA approval of empagliflozin included a requirement for postmarketing studies that are currently continuing, and the results are not yet available. ${ }^{12}$

EMPA-REG OUTCOMETM is an ongoing randomized, placebo-controlled, cardiovascular outcome trial of empagliflozin that will determine the long-term cardiovascular safety of the drug and potential benefits on macrovascular and microvascular outcomes (ClinicalTrials.gov identifier: NCT01131676). The trial is being conducted in 592 clinical sites where 7,034 patients with T2DM on background antihyperglycemic therapy have been randomized and treated with $10 \mathrm{mg}$ or $25 \mathrm{mg}$ empagliflozin or placebo. ${ }^{39}$

PK and PD properties of empagliflozin are currently being studied in children and adolescents aged 10 to less than 18 years with T2DM to identify a safe and effective dose of the drug in this patient category (ClinicalTrials.gov identifier: NCT02121483).

The efficacy and safety of empagliflozin $(10 \mathrm{mg} /$ day or $25 \mathrm{mg} /$ day) in African-American T2DM individuals with hypertension is being investigated in a randomized, double-blind, placebo-controlled, parallel-group manner (ClinicalTrials.gov identifier: NCT02182830). Primary efficacy end point is a reduction in $\mathrm{HbA}_{1 \mathrm{c}}$ at week 24 with secondary end points of decreases in systolic and diastolic BPs at 12 weeks and 24 weeks.

The safety and efficacy of the drug are also being studied in Japanese elderly (aged 65 and over) patients with T2DM (ClinicalTrials.gov identifier: NCT02367131). 


\section{Specific patient profiles suited to the treatment with empagliflozin}

Because of the favorable interaction with other anti-hyperglycemic agents and the unique mechanism of action that does not involve insulin, empagliflozin can be used as a monotherapy or as part of combination treatment in most patient categories with any stage of T2DM. The following paragraphs describe examples of specific patient profiles that would be suited to the treatment with empagliflozin.

\section{Patient profile \#I}

Jane is a 52 -year-old female with $\sim 10$-year history of T2DM. She is $5^{\prime} 3^{\prime \prime}$ and weighs $190 \mathrm{lb}$; her most recent $\mathrm{HbA}_{1 \mathrm{c}}$ was $9.1 \%$ and BP $162 / 92 \mathrm{mmHg}$. She is currently taking metformin $1,000 \mathrm{mg}$ bid and glipizide $20 \mathrm{mg}$ /day for diabetes and enalapril $20 \mathrm{mg} /$ day for hypertension.

\section{Patient profile \#2}

Tom is an overweight 62-year-old African-American man who was diagnosed with T2DM 16 years ago. He finds it difficult to adhere to diet and exercise recommendations. His clinical and laboratory parameters are as follows: $\mathrm{BP}$ 156/84 mmHg, BMI $37 \mathrm{~kg} / \mathrm{m}^{2}, \mathrm{HbA}_{\mathrm{lc}} 8.4 \%$, and FPG $132 \mathrm{mg} /$ dL. He was started on insulin 2 years ago, currently taking insulin glargine 48 IU/day.

\section{Patient profile \#3}

Saul is a 49-year-old man who has a 5-year history of T2DM. Initially managed with lifestyle modification, he was started on metformin 2 years ago, presently taking $2,000 \mathrm{mg} /$ day. $\mathrm{He}$ also takes ramipril $5 \mathrm{mg}$ /day for hypertension. His BP is $138 / 82 \mathrm{mmHg}$, BMI $36 \mathrm{~kg} / \mathrm{m}^{2}, \mathrm{HbA}_{\mathrm{lc}} 7.3 \%$, FPG $129 \mathrm{mg} / \mathrm{dL}$, and 2-hour PPG $166 \mathrm{mg} / \mathrm{dL}$, and urine albumin is within normal limits.

\section{Patient profile \#4}

JN is a 59-year-old woman with T2DM diagnosed in 1998, hypertension, hyperlipidemia, and asthma. She was initially treated with metformin and lifestyle modification and was switched to insulin $\sim 5$ years ago. She is treated with Humalog 75/25, 31 units before breakfast and 27 units before dinner. Her other medications include lisinopril $30 \mathrm{mg} /$ day, fluvastatin $20 \mathrm{mg}$ at bedtime, fluticasone MDI 4 puffs/day, and levalbuterol two inhalations every 5 hours. Because of the exacerbation of asthma, she requires prednisone therapy. Physical examination and lab results include weight $299 \mathrm{lb}$, height 5'4", BP 131/81 mmHg, $\mathrm{HbA}_{1 \mathrm{c}} 7.1 \%$, FPG $131 \mathrm{mg} / \mathrm{dL}$, LDL cholesterol $114 \mathrm{mg} / \mathrm{dL}$, and HDL cholesterol $49 \mathrm{mg} / \mathrm{dL}$.

\section{Patient profile \#5}

Linda is a 44-year-old Hispanic obese female diagnosed with T2DM 7 years ago. She is currently taking metformin $1,500 \mathrm{mg} /$ day and glimepiride $4 \mathrm{mg} /$ day. Her most recent $\mathrm{HbA}_{1 \mathrm{c}}$ was $7.9 \%$, FPG was $131 \mathrm{mg} / \mathrm{dL}$, and BP was 129/78 mmHg.

\section{Conclusion and place in therapy}

In adult T2DM individuals, empagliflozin is characterized by rapid absorption reaching peak levels in $\sim 2$ hours, ${ }^{15}$ dose proportional exposure, inhibition of glucose reabsorption, and increase in UGE. Empagliflozin produces clinically meaningful improvements in $\mathrm{HbA}_{1 \mathrm{c}}$ and FPG without increasing risk of hypoglycemia. The drug is also associated with significant reductions in body weight and systolic BP. Empagliflozin can be used as a monotherapy or in combination with one or two other oral agents or insulin. Although FDA has approved empagliflozin as the first-line therapy, according to the position statement of ADA and EASD, SGLT2 inhibitors are more likely to be used in combination with metformin and/or other medications. ${ }^{1}$

Glycemic efficacy of empagliflozin is comparable to other approved members of the class. Reductions in $\mathrm{HbA}_{1 \mathrm{c}}$ have been shown to be $\sim-0.9 \%$ with canagliflozin, ${ }^{40} \sim 0.8 \%$ with dapagliflozin, ${ }^{41}$ and $\sim 1 \%$ with ipragliflozin. ${ }^{42}$ Weight loss also appears to be similar to other SGLT2 inhibitors: canagliflozin $\sim-2.9 \mathrm{~kg},{ }^{40}$ dapagliflozin $\sim-2.6 \mathrm{~kg},{ }^{43}$ and ipragliflozin $\sim-2 \mathrm{~kg} .{ }^{42}$ Most common side effects associated with empagliflozin were genital and urinary tract infections, which were also reported in trials with dapagliflozin and canagliflozin. ${ }^{44,45}$

In conclusion, empagliflozin taken as a single medication or as add-on to other common anti-hyperglycemic agents (including insulin) is safe, well tolerated, and effective and has additional clinical benefits of weight loss and reductions in BP. Ongoing cardiovascular outcome studies will reveal long-term safety and efficacy of the drug. ${ }^{39}$

\section{Disclosure}

The authors have no financial conflicts of interest to declare. The manuscript was written in the absence of any commercial or financial relationships.

\section{References}

1. Inzucchi SE, Bergenstal RM, Buse JB, et al. Management of hyperglycemia in type 2 diabetes, 2015: a patient-centered approach: update to a position statement of the American Diabetes Association and the European Association for the Study of Diabetes. Diabetes Care. 2015; 38(1):140-149.

2. Inzucchi SE, Bergenstal RM, Buse JB, et al. Management of hyperglycemia in type 2 diabetes: a patient-centered approach: position statement of the American Diabetes Association (ADA) and the European Association for the Study of Diabetes (EASD). Diabetes Care. 2012; 35(6):1364-1379. 
3. Cryer PE, Davis SN, Shamoon H. Hypoglycemia in diabetes. Diabetes Care. 2003;26(6):1902-1912.

4. Nathan DM, Buse JB, Davidson MB, et al; American Diabetes Association; European Association for the Study of Diabetes. Medical management of hyperglycaemia in type 2 diabetes mellitus: a consensus algorithm for the initiation and adjustment of therapy. A consensus statement from the American Diabetes Association and the European Association for the Study of Diabetes. Diabetologia. 2009;52(1):17-30.

5. Phung OJ, Sobieraj DM, Engel SS, Rajpathak SN. Early combination therapy for the treatment of type 2 diabetes mellitus: systematic review and meta-analysis. Diabetes Obes Metab. 2014;16(5):410-417.

6. Kovacs CS, Seshiah V, Swallow R, et al. Empagliflozin improves glycaemic and weight control as add-on therapy to pioglitazone or pioglitazone plus metformin in patients with type 2 diabetes: a 24-week, randomized, placebo-controlled trial. Diabetes Obes Metab. 2014;16(2):147-158.

7. Häring HU, Merker L, Seewaldt-Becker E, et al; EMPA-REG METSU Trial Investigators. Empagliflozin as add-on to metformin plus sulfonylurea in patients with type 2 diabetes: a 24-week, randomized, double-blind, placebo-controlled trial. Diabetes Care. 2013;36(11): 3396-3404

8. Nelson JM, Dufraux K, Cook PF. The relationship between glycemic control and falls in older adults. $J$ Am Geriatr Soc. 2007;55(12): 2041-2044.

9. Wright EM, Hirayama BA, Loo DF. Active sugar transport in health and disease. J Intern Med. 2007;261(1):32-43.

10. Vasilakou D, Karagiannis T, Athanasiadou E, et al. Sodium-glucose cotransporter 2 inhibitors for type 2 diabetes a systematic review and meta-analysis. Ann Intern Med. 2013;159(4):262-274.

11. Rosenstock J, Seman LJ, Jelaska A, et al. Efficacy and safety of empagliflozin, a sodium glucose cotransporter 2 (SGLT2) inhibitor, as add-on to metformin in type 2 diabetes with mild hyperglycaemia. Diabetes Obes Metab. 2013;15(12):1154-1160.

12. US Food and Drug Administration. FDA approves Jardiance to treat type 2 diabetes [press release]. Silver Spring, MD: US Food and Drug Administration; 2014 [August 1]. Available from: http://www.fda. gov/NewsEvents/Newsroom/PressAnnouncements/ucm407637.htm. Accessed February 25, 2015.

13. Jardiance ${ }^{\circledR}$ (empagliflozin) [prescribing information]. Ingelheim: Licensed from: Boehringer Ingelheim International GmbH; 2014.

14. Grempler R, Thomas L, Eckhardt M, et al. Empagliflozin, a novel selective sodium glucose cotransporter-2 (SGLT-2) inhibitor: characterisation and comparison with other SGLT-2 inhibitors. Diabetes Obes Metab. 2012;14(1):83-90.

15. Komoroski B, Vachharajani N, Boulton D, et al. Empagliflozin (BI 10773), a potent and selective SGLT2 inhibitor, induces dose-dependent glucosuria in healthy subjects. Clin Pharmacol Drug Dev. 2013;2(2): 152-161.

16. Sarashina A, Koiwai K, Seman LJ, et al. Safety, tolerability, pharmacokinetics and pharmacodynamics of single doses of empagliflozin, a sodium glucose cotransporter 2 (SGLT2) inhibitor, in healthy Japanese subjects. Drug Metab Pharmacokinet. 2013;28(3):213-219.

17. Heise T, Seewaldt-Becker E, Macha S, et al. Safety, tolerability, pharmacokinetics and pharmacodynamics following 4 weeks' treatment with empagliflozin once daily in patients with type 2 diabetes. Diabetes Obes Metab. 2013;15(7):613-621.

18. Heise T, Seman L, Macha S, et al. Safety, tolerability, pharmacokinetics, and pharmacodynamics of multiple rising doses of empagliflozin in patients with type 2 diabetes mellitus. Diabetes Ther. 2013;4(2):331-345.

19. Brand T, Macha S, Mattheus M, Pinnetti S, Woerle HJ. Pharmacokinetics of empagliflozin, a sodium glucose cotransporter-2 (SGLT-2) inhibitor, coadministered with sitagliptin in healthy volunteers. $A d v$ Ther. 2012;29(10):889-899.

20. Friedrich C, Metzmann K, Rose P, Mattheus M, Pinnetti S, Woerle HJ. A randomized, open-label, crossover study to evaluate the pharmacokinetics of empagliflozin and linagliptin after coadministration in healthy male volunteers. Clin Ther. 2013;35(1):A33-A42.
21. Scott LJ. Empagliflozin: a review of its use in patients with type 2 diabetes mellitus (vol 74, pg 1769, 2014). Drugs. 2015;75(1):141-141.

22. Kadowaki T, Haneda M, Inagaki N, et al. Empagliflozin monotherapy in Japanese patients with type 2 diabetes mellitus: a randomized, 12-week, double-blind, placebo-controlled, phase II trial. Adv Ther. 2014;31(6): 621-638.

23. Woerle HJ, Kadowaki T, Haneda M, et al. Safety and efficacy of empagliflozin monotherapy in a 52-week study in Japanese patients with type 2 diabetes mellitus. Poster No. 930 presented at: 49th Annual Meeting of the European Association for the Study of Diabetes; September 23-27, 2013; Barcelona.

24. Ferrannini E, Seman L, Seewaldt-Becker E, Hantel S, Pinnetti S, Woerle HJ. A phase IIb, randomized, placebo-controlled study of the SGLT2 inhibitor empagliflozin in patients with type 2 diabetes. Diabetes Obes Metab. 2013;15(8):721-728.

25. Roden M, Weng J, Eilbracht J, et al; EMPA-REG MONO Trial Investigators. Empagliflozin monotherapy with sitagliptin as an active comparator in patients with type 2 diabetes: a randomised, double-blind, placebo-controlled, phase 3 trial. Lancet Diabetes Endocrinol. 2013; 1(3):208-219.

26. Nishimura R, Tanaka Y, Koiwai K, et al. Effect of empagliflozin monotherapy on postprandial glucose and 24-hour glucose variability in Japanese patients with type 2 diabetes mellitus: a randomized, double-blind, placebo-controlled, 4-week study. Cardiovasc Diabetol. 2015;14(1):11.

27. Haring HU, Merker L, Seewaldt-Becker E, et al. Empagliflozin as add-on to metformin in patients with type 2 diabetes: a 24-week, randomized, double-blind, placebo-controlled trial. Diabetes Care. 2014; 37(6): 1650-1659.

28. Ferrannini E, Berk A, Hantel S, et al. Long-term safety and efficacy of empagliflozin, sitagliptin, and metformin: an active-controlled, parallelgroup, randomized, 78-week open-label extension study in patients with type 2 diabetes. Diabetes Care. 2013;36(12):4015-4021.

29. Ridderstråle M, Svaerd R, Zeller C, et al. Empagliflozin (EMPA) for $\geq 76$ weeks as add-on to metformin plus sulfonylurea (SU) in patients with type 2 diabetes (T2DM). Diabetes. 2014;63(suppl 1):A280. [abstract no.1077-P].

30. Kovacs CS, Seshiah V, Merker L, et al. Empagliflozin (EMPA) for $\geq 76$ weeks as add-on to pioglitazone with or without metformin in patients with type 2 diabetes (T2DM). Diabetes. 2014;63(suppl 1):A273. [abstract no.1055-P].

31. Rosenstock J, Jelaska A, Wang F, Kim G, Broedl UC, Woerle HJ. Empagliflozin as add-on to basal insulin for 78 weeks improves glycaemic control with weight loss in insulin-treated type 2 diabetes mellitus. Diabetologia. 2013;56:S372-S372.

32. Rosenstock J, Jelaska A, Frappin G, et al; EMPA-REG MDI Trial Investigators. Improved glucose control with weight loss, lower insulin doses, and no increased hypoglycemia with empagliflozin added to titrated multiple daily injections of insulin in obese inadequately controlled type 2 diabetes. Diabetes Care. 2014;37(7):1815-1823.

33. Hach T, Gerich J, Salsali A, et al. Empagliflozin improves glycaemic parameters and cardiovascular risk factors in patients with type 2 diabetes: pooled data from four pivotal phase III trials. Poster No: 943 presented at: the European Association for the Study of Diabetes (EASD); September 23-27, 2013; Barcelona.

34. Dailey G. Empagliflozin for the treatment of type 2 diabetes mellitus: an overview of safety and efficacy based on phase 3 trials. J Diabetes. Epub 2015 Feb 11.

35. Barnett AH, Mithal A, Manassie J, et al; EMPA-REG RENAL Trial Investigators. Efficacy and safety of empagliflozin added to existing antidiabetes treatment in patients with type 2 diabetes and chronic kidney disease: a randomised, double-blind, placebo-controlled trial. Lancet Diabetes Endocrinol. 2014;2(5):369-384.

36. Macha S, Rose P, Mattheus M, et al. Pharmacokinetics, safety and tolerability of empagliflozin, a sodium glucose cotransporter 2 inhibitor, in patients with hepatic impairment. Diabetes Obes Metab. 2014;16(2): $118-123$. 
37. Tikkanen I, Narko K, Zeller C, et al; EMPA-REG BP Investigators. Empagliflozin reduces blood pressure in patients with type 2 diabetes and hypertension. Diabetes Care. 2015;38(3):420-428.

38. Liakos A, Karagiannis T, Athanasiadou E, et al. Efficacy and safety of empagliflozin for type 2 diabetes: a systematic review and metaanalysis. Diabetes Obes Metab. 2014;16(10):984-993.

39. Zinman B, Inzucchi SE, Lachin JM, et al. Rationale, design, and baseline characteristics of a randomized, placebo-controlled cardiovascular outcome trial of empagliflozin (EMPA-REG OUTCOME). Cardiovasc Diabetol. 2014;13:102.

40. Stenlöf K, Cefalu WT, Kim KA, et al. Efficacy and safety of canagliflozin monotherapy in subjects with type 2 diabetes mellitus inadequately controlled with diet and exercise. Diabetes Obes Metab. 2013; 15(4):372-382.

41. Kanai Y, Lee WS, You G, Brown D, Hediger MA. The human kidney low affinity $\mathrm{Na}+$ /glucose cotransporter SGLT2. Delineation of the major renal reabsorptive mechanism for D-glucose. J Clin Invest. 1994;93(1): $397-404$.
42. Hedrington MS, Davis SN. Ipragliflozin, a sodium-glucose cotransporter 2 inhibitor, in the treatment of type 2 diabetes. Expert Opin Drug Metab Toxicol. 2015;11(4):613-623.

43. Bailey CJ, Morales Villegas EC, Woo V, Tang W, Ptaszynska A, List JF. Efficacy and safety of dapagliflozin monotherapy in people with type 2 diabetes: a randomized double-blind placebo-controlled 102-week trial. Diabet Med. 2015;32(4):531-541.

44. Nyirjesy P, Zhao Y, Ways K, Usiskin K. Evaluation of vulvovaginal symptoms and Candida colonization in women with type 2 diabetes mellitus treated with canagliflozin, a sodium glucose co-transporter 2 inhibitor. Curr Med Res Opin. 2012;28(7):1173-1178.

45. Bailey CJ, Gross JL, Pieters A, Bastien A, List JF. Effect of dapagliflozin in patients with type 2 diabetes who have inadequate glycaemic control with metformin: a randomised, double-blind, placebo-controlled trial. Lancet. 2010;375(9733):2223-2233.
Therapeutics and Clinical Risk Management

\section{Publish your work in this journal}

Therapeutics and Clinical Risk Management is an international, peerreviewed journal of clinical therapeutics and risk management, focusing on concise rapid reporting of clinical studies in all therapeutic areas, outcomes, safety, and programs for the effective, safe, and sustained use of medicines. This journal is indexed on PubMed Central, CAS,

\section{Dovepress}

EMBase, Scopus and the Elsevier Bibliographic databases. The manuscript management system is completely online and includes a very quick and fair peer-review system, which is all easy to use. Visit http://www.dovepress.com/testimonials.php to read real quotes from published authors.

Submit your manuscript here: http://www.dovepress.com/therapeutics-and-clinical-risk-management-journal 